\title{
EL INSTITUTO PEDAGÓGICO NACIONAL Y LA EDUCACIÓN DE LA MUJER: $1927-1936^{*}$
}

\author{
Víctor Manuel Prieto V. \\ Universidades Incca de Colombia y Libre
}

\section{Introducción}

Durante los años veinte, época conocida en nuestra historia como la danza de los millones y la prosperidad al debe, en la sociedad colombiana se presentaron rápidas transformaciones en el orden económico, político y cultural. La consolidación del café en el mercado internacional, la indemnización que recibió el país de parte de Estados Unidos por la separación de Panamá en 1924, y los préstamos adquiridos en el sistema financiero internacional permitieron hacer inversiones en la ampliación y mejoramiento de la infraestructura y los servicios públicos de algunas regiones; se estimuló el desarrollo industrial y comercial y el crecimiento de ciudades como Medellín, Barranquilla, Cali y Bogotá $^{49}$. Así se inició la lenta transición de una sociedad rural a una urbana, pues ese proceso creaba expectativas para la inversión en la industria y el comercio; y gracias a la organización centralista que la Constitución Política de 1886 le dio al país, Bogotá volvió a legitimar nuevamente su posición política.

Esos síntomas de modernización obligaron al Estado a promover reformas en la educación buscando ampliar su cobertura y modificar los métodos y contenidos de la enseñanza para articularla a las nuevas condiciones sociales. Algunos dirigentes propusieron empezar por la preparación de los profesores que más adelante estuvieran en capacidad de ejecutar las políticas que diseñara el gobierno central.

La Ley 25 de $1917^{50}$, por ejemplo, dispuso la creación de dos Institutos Pedagógicos Nacionales para institutores en Bogotá, uno masculino y el otro femenino, para formar allí a maestros y maestras de diferentes regiones, dentro de concepciones pedagógicas modernas, medida que no se ejecutó sino parcialmente y, diez años después, cuando la propuesta se volvió a discutir a raíz de las recomendaciones formuladas por la segunda Misión Pedagógica Alemana contratada por el gobierno en 1924. Hasta ese momento las escuelas normales habían estado bajo la dirección de las comunidades religiosas y la formación de los maestros no parece haber sido muy importante para el Estado en la época pues, como se verá más adelante, desde 1919 se asignaron los terrenos para iniciar la organización de uno de esos institutos, pero nadie se puso al frente de esa empresa.

Los alemanes trabajaron en la evaluación del sistema educativo y en el diseño de las políticas que debían guiar una reforma, conjuntamente con tres profesores colombianos,

\footnotetext{
* Este ensayo es la versión revisada de la ponencia presentada con el mismo título en el III Congreso iberoamericano de historia de la educación latinoamericana realizado en Caracas, Venezuela del 9 al 14 de junio de 1996.

${ }_{49}$ Luis Ospina Vásquez, Industria y protección en Colombia, Editorial Faes, Medellín, 1979, págs. 355-378.

${ }^{50}$ Francisca Radke, Historia del Instituto Pedagógico Nacional para señoritas, Editorial El Gráfico, Bogotá, 1936, págs 6-8; Antonio José Uribe, Instrucción pública, Imprenta Nacional, Bogotá, 1972, págs. 258-262. 
dos de ellos conservadores y uno liberal ${ }^{51}$. Advirtiendo la influencia ideológica y cultural que ejercía el clero en la sociedad, y los privilegios que la Constitución Política de 1886 y el Concordato firmado con la Santa Sede al año siguiente le otorgaban a la Iglesia, los miembros de la Misión Pedagógica buscaron evitar polémicas con las altas jerarquías eclesiásticas, pues desde el siglo XIX ese había sido uno de los motivos de conflicto entre los partidos políticos. Era tal el interés del clero en defender sus privilegios en la educación que durante los gobiernos de los radicales, cuando el Estado trató de limitárselos, los curas se convirtieron en los principales opositores de esa reforma ${ }^{52}$. Con esos antecedentes los miembros de la Segunda Misión Pedagógica Alemana no cuestionaron los privilegios de la Iglesia en la educación, pero si enfatizaron la necesidad de ampliar la cobertura escolar, de especializar la formación secundaria y de mejorar la formación de los maestros ${ }^{53}$.

Sin embargo, y como expresión del sectarismo y de las rivalidades entre los partidos, la actitud de respeto de los miembros de la misión para con los fueros de la Iglesia no fue suficiente para neutralizar el fanatismo y las pasiones políticas y religiosas de los grupos más tradicionales de la sociedad colombiana. Sus recomendaciones tuvieron que enfrentar la oposición del clero y de un sector del partido conservador, quienes argumentando que el proyecto de reforma educativa que se le presentó al Congreso de la República en 1925 era nocivo para los valores morales y espirituales del país impidieron su aprobación. Al año siguiente, y luego de haber sido revisado se sometió a discusión ante el parlamento nuevamente. La segunda vez lo rechazaron los liberales aludiendo que con esas modificaciones se le estaban ampliando las prebendas a la Iglesia en la educación ${ }^{54}$.

Ante esa situación y apartándose de esas polémicas, algunos dirigentes políticos que comprendieron la importancia de modernizar la educación pensaron en promover reformas parciales, entre las cuales figuró la creación de una Escuela Normal en Bogotá. Para iniciar su organización sus promotores recurrieron a la Ley 25 de 1917, en donde se ordenaba la creación de los dos Institutos Pedagógicos Nacionales, así pudieron captar los recursos oficiales que se requerían para la organización del Instituto Pedagógico Nacional para señoritas, plantel que empezó a funcionar en 1927.

Con un colegio dirigido por pedagogos, laicos para preparar algunas profesoras con métodos de enseñanza modernos y dándole un carácter nacional, como ocurrió con el Instituto Pedagógico Nacional para señoritas, se estaba dando un primer paso en la intención de reformar la educación, pues las maestras que se formaran allí serían necesarias más adelante para ejecutar parte de las recomendaciones de la Misión

\footnotetext{
${ }^{51}$ Los miembros de la Segunda Misión Pedagógica fueron los alemanes Anton Eitel, Karl Gloeckner y Karl Decker y los colombianos Emilio Ferrero, Gerardo Arrubla y Tomás Rueda Vargas. Ingrid Müller de Ceballos, La lucha por la cultura: la formación del maestro colombiano en una perspectiva internacional, tomo 1, Universidad Pedagógica Nacional, Santafé de Bogotá, 1992, pág. 39.

52 La primera propuesta de reforma educativa asesorada por una Misión Pedagógica Alemana fue emprendida por los gobiernos radicales del siglo anterior, pero fracasó debido a la oposición que le hicieron el clero y el partido conservador. Un estudio sobre el tema puede verse en: Jane M. Rausch, La educación durante el federalismo, Instituto Caro y Cuervo, Universidad Pedagógica Nacional, Santafé de Bogotá, 1993. Ingrid Müller de Ceballos hace una cuidadosa comparación del Decreto Orgánico de Instrucción pública de 1870 que expresaba los anhelos de reforma de los radicales y el Decreto 419 de 1904 que reglamentaba la Ley Orgánica 39 de 1903 que expresaban las pretensiones de los gobiernos de la regeneración, donde su principal inspirador el dirigente conservador Antonio José Uribe, omite citar la semejanza de estas dos medidas. Ingrid Müller de Ceballos, Op. cit., págs. 42-50.

${ }^{53} \mathrm{lbí}$ dem. págs. 39-86.

${ }^{54}$ Aline Helg, La educación en Colombia: 1918-1957: una historia social, económica y política, Fondo Editorial Cerec, Bogotá, 1987, págs. 116-119.
} 
Pedagógica. A pesar de las dificultades que tuvo que soportar este colegio para su organización, el apoyo del Estado a la iniciativa de sus directores fue fundamental; pues durante sus primeros años logró destacarse por la eficacia de sus métodos de enseñanza. Algunos trabajos han señalado el papel que desempeñó este plantel en la formación del magisterio, llegando al punto de constituirse en una de las primeras instituciones que le ofreció educación de calidad a la mujer en Colombia ${ }^{55}$.

\section{Orígenes, organización y dotación}

Para la construcción de su sede se destinó un terreno que había sido donado por el municipio de Bogotá a la nación en 1919 para la creación de una de las Escuelas Normales que de acuerdo con lo dispuesto en 1917 debía organizarse en la ciudad. El diseño de su planta física estuvo a cargo del arquitecto Pablo de la Cruz, quien siguiendo las recomendaciones de los pedagogos europeos y norteamericanos lo proyectó como un colegio campestre ajustado técnica y estéticamente a los requerimientos de un establecimiento educativo moderno ${ }^{56}$, lo cual no era, ni suele ser en la actualidad, muy común en la planificación de los edificios donde funcionan los planteles oficiales y que debido a las constantes y no siempre adecuadas remodelaciones impidió la conservación de su estructura arquitectónica original.

Inicialmente el colegio estuvo ubicado en la Avenida Chile con carrera 11, donde está operando actualmente la Universidad Pedagógica Nacional, lugar que por esa época eran las afueras de la ciudad, y a unas pocas cuadras del Gimnasio Moderno, establecimiento privado fundado por algunos miembros del partido liberal en 1914 para formar a un sector de la élite, y que a diferencia del Instituto Pedagógico Nacional, conservó su diseño original y en 1978 fue declarado patrimonio arquitectónico del país.

El Instituto inició labores en 1927, año en el cual fue clausurada la Escuela Normal para Mujeres de Cundinamarca, establecimiento que habían creado con un propósito similar los gobiernos radicales en 1872 dentro de su política de reforma educativa ${ }^{57}$. El colegio abrió sus puertas sin que su construcción estuviera completamente terminada, pero durante los primeros años se le asignaron recursos suficientes para dotarlo de una planta física adecuada para una escuela modelo ${ }^{58}$. Entre 1927 y 1936 se instalaron los servicios públicos, se dispusieron espacios para realizar las actividades que recomendaban los promotores del movimiento de la Escuela Activa y se construyeron nuevas dependencias para el servicio de las alumnas y para organizar las prácticas pedagógicas. La Escuela Anexa fue edificada entre 1927 y 1929, en 1932 se compró el resto de la manzana para ampliar la planta física y en 1933 se construyeron el Jardín Infantil y las residencias en donde se debían alojar las nuevas alumnas internas ${ }^{59}$.

La reforma educativa emprendida durante la primera administración de Alfonso López Pumarejo (1934-1938) retomó las propuestas de la Misión Pedagógica Alemana y para promoverlas se pensó en capacitar a los maestros ${ }^{60}$. Aprovechando la experiencia del Instituto Pedagógico Nacional se organizó un programa con ese fin y se alquiló una casa

\footnotetext{
${ }^{55}$ Ver por ejemplo, Ibídem, págs. 125-127 y Ingrid Müller de Ceballos, Op. cit. págs. 107-124.

${ }^{56}$ El Instituto Pedagógico Nacional 50 años, Bogotá, Instituto Pedagógico Nacional, 1977, pág. 14.

${ }^{57}$ Francisca Radke, Op. cit., pág 5.

${ }^{58}$ Su directora escribía que, "el Instituto Pedagógico se abrió el 9 de marzo de 1927, sin luz, sin agua, ni mobiliario. Se dormía sobre colchones colocados en el suelo; la noche se alumbraba con espermas y, más tarde, con lámparas de petróleo; la Avenida Chile estaba sin urbanizar, y el mismo barrio de Chapinero tan lejos de Bogotá como cualquier otra ciudad'. Ibídem, pág. 13.

${ }^{59}$ Ibídem., págs. 8-9.

${ }^{60}$ Aline Helg, Op. cit., págs. 149-152. 
vecina para hospedar a las maestras que viajaban a Bogotá a tomar Cursos de Información para prepararlas buscando promover reformas en el sistema educativo oficial. El mismo año se construyeron los locales para la Escuela Montessori y para el Kindergarten ${ }^{61}$ ampliando los servicios que ofrecía el colegio y de nuevos sitios para las prácticas pedagógicas. En 1936 el establecimiento contaba con una casa principal con 16 aulas de clase, capilla, biblioteca, museo, gabinete de física, dormitorios para alumnas, empleadas y profesoras, baños, piscina, cocina, enfermería y dentistería, pues su carácter nacional exigía aumentar los cupos para que ingresaran alumnas de diferentes regiones del país ${ }^{62}$.

Como inicialmente las alumnas y profesoras eran internas, una de las preocupaciones de su directora fue velar porque encontraran en el colegio un lugar familiar, cómodo y agradable durante el tiempo que estuvieran lejos de sus hogares. Siguiendo las recomendaciones del movimiento de la Escuela Activa, que planteaba que el ambiente escolar debía constituirse en un instrumento de formación estética y moral, le concedió atención particular a su decoración y a su ambiente social. Los equipos, materiales didácticos y elementos para dotar el gimnasio y los laboratorios fueron importados de Estados Unidos y Alemania, pues en el país aún no se producían. Y en sus patios, además de la organización de prados y jardines, se adecuaron espacios para la horticultura, la gimnasia y la práctica deportiva. Durante los primeros años de funcionamiento el Instituto Pedagógico para señoritas fue equipado hasta el punto de llegar a ser considerado uno de los planteles oficiales mejor dotados del país.

\section{Personal vinculado al Instituto}

Además de sus buenas condiciones locativas se requería una adecuada selección de sus docentes para imprimirle el espíritu de una escuela moderna. Como el país carecía de profesores preparados competentemente, el gobierno decidió traerlos del extranjero encomendando al médico Miguel Jiménez López, quien se desempeñaba como embajador en Berlín, la contratación de seis profesores alemanes, siempre y cuando fueran católicos ${ }^{63}$. Estos docentes orientaron su actividad dentro de los métodos de la Escuela Activa, movimiento que desde principios de siglo $X X$ fue considerado como una de las alternativas pedagógicas más avanzadas a nivel internacional, pero que en Colombia tuvo mucha resistencia entre los sectores ultraconservadores, quienes lo veían inadecuado para la enseñanza y peligroso para la formación moral de los estudiantes, por tanto, esa orientación se seguía solamente en algunos colegios privados.

Pero gracias a su organización académica y a la formación de los profesores que se contrataron, el Instituto Pedagógico Nacional contribuyó en la difusión de esos métodos en Colombia diseñando actividades escolares que eran presentadas a las alumnas como modelo de enseñanza en el preescolar y la primaria de sus escuelas anexas y para formarlas dentro de esas mismas concepciones esperando que los aplicaran cuando empezaran a desempeñarse como maestras.

\footnotetext{
${ }^{61}$ Francisca Radke, Op. cit., pág. 8.

${ }^{62}$ La ampliación de cupos en el Instituto también se debió a que la crisis económica de 1929 obligó al Estado a cerrar las escuelas normales departamentales y para resolver en algo la situación amplió los cupos para recibir alumnas de todas las regiones del país. Aline Helg. Op. cit., pág. 126.

${ }^{63}$ Ibídem, pág. 9. 
La dirección del Instituto Pedagógico se le encomendó a la pedagoga alemana Francisca Radke, quien poseía la preparación académica, la experiencia docente y la capacidad de organización suficientes para desempeñar esta función ${ }^{64}$. Con ella llegaron las profesoras María Hasebrink, Karolina Schmidt, Gertrud Fuesers y los profesores Richard Ostermayr y Hans Huber. La nómina se completó con varios profesores contratados en Colombia. Algunos de ellos, como Tomás Rueda Vargas, Rafael Mallarino, Manuel Piquero y Henry Yerly estaban vinculados al Gimnasio Moderno; los primeros eran miembros de prestantes familias de la capital y no tenían formación pedagógica, Piquero y Yerly sí la poseían, pues se habían formado dentro de las orientaciones de la Escuela Activa en Europa, razón por la cual fueron contratados por este colegio. Además, estos docentes conocían las propuestas de la Escuela Activa, pues en el Gimnasio Moderno se estaban aplicando desde 1914 y sus promotores venían atribuyéndose además el haberlos introducido en Colombia ${ }^{65}$.

Con un equipo docente familiarizado con métodos de enseñanza modernos y con los recursos materiales suficientes para aplicarlos, el Instituto Pedagógico se constituyó en la primera institución oficial en condiciones de ofrecerle educación de calidad a la mujer colombiana, pues en una sociedad que empezaba a urbanizarse ya no se le podía seguir educando para que se desempeñara solamente como madre y esposa. La naturaleza femenina del colegio obedeció a que la docencia fue una de las pocas actividades socialmente aceptadas para que las jóvenes de clase media se desempeñaran laboralmente durante la primera mitad del siglo XX, pues se consideraba que, por encima de la formación académica, su espíritu maternal la hacia apta para ejercer un oficio que era visto como la prolongación de las labores del hogar ${ }^{66}$. Y dado su carácter nacional, las alumnas se seleccionaron entre candidatas que procedían de diferentes regiones, esperando que, una vez terminados sus estudios, regresaran a sus lugares de origen a ejercer la docencia con la formación suficiente para aplicar los métodos de la Escuela Activa, buscando que contribuyeran a lo que algunos dirigentes políticos esperaban convertir en una reforma educativa de carácter nacional ${ }^{67}$.

Ante la falta de trayectoria del plantel, la poca disposición de la sociedad para ofrecerle educación a la mujer y buscando atraer a las primeras estudiantes, para su apertura el Estado otorgó 80 becas. Por derecho propio 31 se le asignaron a las alumnas que cursaban estudios en la Escuela Normal de Cundinamarca que se clausuró el mismo año de la creación del Instituto Pedagógico. Para establecer un criterio de selección que facilitara conceder las otras becas, se convocó a un concurso público donde se le hizo un examen a las jóvenes que se inscribieron aplicándoles varios tests de Telman que arrojaron pésimos resultados. Pero la directora consideró que las aspirantes de mayor calificación debían ingresar, pues los malos puntajes de las pruebas no se debieron a la falta de capacidad intelectual de las candidatas sino a que no estaban acostumbradas a ese tipo de exámenes. Francisca Radke argumentaba que en las entrevistas notó que venían de un sistema educativo deficiente, pues a su juicio, se habían formado en

\footnotetext{
${ }^{64}$ Una breve pero ilustrativa reseña de la formación académica de Francisca Radke puede verse en el trabajo citado de Ingrid Müller de Ceballos, pág. 89.

${ }^{65}$ La historia de este plantel ha sido tratada en Víctor Manuel Prieto, "El Gimnasio Moderno y la formación de la élite liberal bogotana, tesis de Maestría de Historia de Colombia, Universidad Nacional, Bogotá, 1996.

${ }^{66} \mathrm{~A}$ la mujer no se le permitió acceso a la educación superior sino hasta la administración de Enrique Olaya Herrera mediante el Decreto 1.874 de 1932. Magdalena Velásquez Toro, "Condición jurídica y social de la mujer", en Nueva Historia de Colombia, tomo IV, Editorial Planeta, Bogotá, 1989, pág. 26.

${ }^{67}$ Esta afirmación puede resultar apresurada para 1927, pero con la llegada del partido liberal al poder en 1930 se iniciaron reformas educativas tendientes a oficializar los métodos de la Escuela Activa. Aline Helg, Op. cit., págs. 135-144.
} 
escuelas con locales inadecuados, que carecían de materiales didácticos aptos para su enseñanza y con unos métodos que enfatizaban en la memorización ${ }^{68}$.

\section{Programas ofrecidos}

El Instituto Pedagógico resultó insuficiente para satisfacer la necesidad de maestras que requería la educación en el país, pero tuvo un rápido crecimiento y ofreció diferentes programas; todos puestos al servicio de la formación pedagógica de las futuras profesoras. El primer año se recibieron 69 alumnas y en 1935 el colegio contaba con 850, además de las 64 niñas que desde 1929 se vincularon a la Escuela Anexa donde se les ofrecían seis años de educación primaría. Esa dependencia tenía cuatro cursos dirigidos por las profesoras alemanas, pero las labores docentes eran atendidas por las alumnas del Instituto Pedagógico como ejercicios prácticos asociados a su formación pedagógica, por tanto, esa sección fue concebida para familiarizarlas con las actividades que proponía la Escuela Activa. Buscando influir en el sistema educativo en 1930 se programaron cursos de información pedagógica para maestras en ejercicio y para los docentes de secundaria que estuvieran dispuestos a recibir orientación en métodos de enseñanza modernos $^{69}$.

El plantel nació durante los últimos años de la hegemonía conservadora, pero se desarrolló considerablemente durante los dos primeros gobiernos liberales de este siglo. En 1933 se abrió la sección Montessori y al año siguiente el jardín infantil, dependencias que además de ampliar los servicios educativos del Instituto Pedagógico debían servir para realizar prácticas en programas que por primera vez ofrecían formación especializada para esos niveles de enseñanza en el país. De esa manera este colegio, no sólo se constituyó en una escuela moderna para educar a la mujer de la naciente clase media para que ingresara al mercado laboral; también inició la expansión de la educación preescolar, que por esa época se ofrecía solamente en las principales ciudades y a la cual tenían acceso únicamente los niños que pertenecían a las familias de la sociedad y, en el mejor de los casos, estaba a cargo de profesoras extranjeras, monjas y maestras que generalmente carecían de los conocimientos pedagógicos para impartirla.

En 1935, cuando las primeras mujeres lograron tener acceso a la universidad y la naciente clase media empezó a preocuparse por la educación de sus hijas, se abrió un curso externo para jóvenes bogotanas, pues muchos padres de familia querían que estudiaran allí sin que tuvieran que ingresar al internado; ese mismo año se le otorgaron tres becas a unas alumnas ecuatorianas dentro de un acuerdo de carácter internacional ${ }^{70}$. La demanda de cupos evidencia la reputación que fue ganando el plantel durante sus primeros años. Y como una muestra de la mentalidad progresista de su primera directora, la profesora Francisca Radke, está su propuesta que no logró ejecutarse, de asignarle cupos a hijas de los obreros para ofrecerle una posibilidad de movilidad social y de bienestar económico a la mujer de un sector que venia siendo marginado de la educación.

\section{Conclusión}

Durante sus primeros años de funcionamiento, el Instituto Pedagógico logró constituirse en una institución líder en la formación de la mujer colombiana. Aplicando los métodos de la Escuela Activa, su educación debía servir como ejemplo de organización y funcionamiento de una escuela moderna, pero la asimilación de las propuestas de esta

\footnotetext{
${ }^{68}$ Instituto Pedagógico Nacional: 50 años, Instituto Pedagógico Nacional, Bogotá, 1977, pág. 14.

${ }^{69}$ Francisca Radke, Op. cit., 18-20.

${ }^{70}$ Ibídem, pág. 29. 
corriente pedagógica debió ajustarse a las condiciones de la cultura de la época, limitando su aplicación. La coeducación y la eliminación de la enseñanza de la religión, por ejemplo, no fueron posibles en una escuela privada como el Gimnasio Moderno, que aún conserva su carácter masculino, ni en una oficial como el Instituto Pedagógico Nacional para señoritas, que sólo hasta la década de los setenta inició la coeducación, pues la resistencia a que hombres y mujeres desempeñaran los mismos roles como la consideración de que su educación en el mismo establecimiento era inadecuada para la moral, impidieron que se tuvieran en cuenta esas recomendaciones. Sin embargo, ambas instituciones fueron concebidas como escuelas experimentales y sirvieron como modelo en la aplicación de esos métodos de enseñanza en el país.

Pero, mientras el Gimnasio Moderno fue fundado para educar a un sector de la élite política y empresarial, el Instituto Pedagógico debía tener otra función. Con su creación se esperaba que al culminar los estudios sus alumnas estuvieran en capacidad de incidir en la ejecución de las reformas que se proponía el Estado. Así debía responder a las necesidades que planteaba la ampliación de la cobertura educativa y a la intención de algunos dirigentes políticos de mejorar la calidad de la enseñanza. A pesar de haber sido pasajero, ese prestigio fue posible gracias al apoyo oficial que recibió el colegio en un período en el cual se creía que, con el crecimiento urbano y e] desarrollo industrial, el país marchaba a un ritmo acelerado hacia la modernización. Pero sus niveles de calidad, como el de otros colegios oficiales que se crearon por la misma época, se perdieron luego de algunos años donde sólo una investigación histórica que desborda la intención de este trabajo puede ofrecer respuestas más precisas. 